Science 335, 835 (2012); DOI: 10.1126/science.1215614

\title{
Supported Iron Nanoparticles as Catalysts for Sustainable Production of
}

\section{Lower Olefins}

Hirsa M. Torres Galvis ${ }^{1}$, Johannes H. Bitter ${ }^{1}$, Chaitanya B. Khare², Matthijs Ruitenbeek ${ }^{2}$, A. Iulian Dugulan ${ }^{3}$, and Krijn P. de Jong ${ }^{1}$ *

${ }^{1}$ Inorganic Chemistry and Catalysis, Utrecht University, Universiteitsweg 99, 3584 CG Utrecht, The Netherlands, ${ }^{2}$ DOW Benelux B.V., P.O. Box 48, 4530 AA Terneuzen, The Netherlands, ${ }^{3}$ Fundamental Aspects of Materials and Energy Group, Delft University of Technology, Mekelweg 15, 2629 JB Delft, The Netherlands. *E-mail: K.P.deJong@uu.nl

Lower olefins are key building blocks for the manufacture of plastics, cosmetics and drugs. Traditionally, olefins with 2 to 4 carbons are produced by steam cracking of crude oil derived naphtha but there is a pressing need for alternative feedstocks and processes in view of supply limitations and of environmental issues. Although the Fischer-Tropsch synthesis has long offered a means to convert coal, biomass and natural gas into hydrocarbon derivatives through the intermediacy of synthesis gas (a mixture of $\mathrm{H}_{2}$ and $\mathrm{CO}$ ), selectivity toward lower olefins tend to be low. Here we report on the conversion of synthesis gas to $C_{2}$ through $C_{4}$ olefins with up to $60 \%$ selectivity by carbon, using catalysts which comprise Fe promoted nanoparticles $(5$ to $30 \mathrm{~nm}$ in diameter) homogeneously dispersed on weakly interactive $\alpha$-alumina or carbon nanofiber supports. 
Lower olefins $\left(\mathrm{C}_{2}\right.$ to $\left.\mathrm{C}_{4}\right)$ are extensively used in the chemical industry as building blocks to synthesize a wide range of products such as polymers, solvents, drugs, cosmetics and detergents. Traditionally, lower olefins have been produced by thermal or catalytic cracking of naphtha or vacuum gas oil (1) or from dehydrogenation of alkanes (2,3), but environmental and economic factors are currently spurring exploration of alternative routes for their production.

In recent years there has been growing interest in the development of biomass as a renewable feedstock for the production of commodity compounds (4,5). Pyrolized biomass or bio-oil can be converted catalytically to lower olefins with moderate selectivity $(43 \% \mathrm{C})(5)$, though significant amounts of other compounds such as aromatics are also produced. Schemes put forward to produce lower olefins from synthesis gas (syngas) - a mixture of $\mathrm{H}_{2}$ and $\mathrm{CO}$ obtained through biomass gasification - consist of at least two conversion steps, which involve either cracking of Fischer-Tropsch (FT) derived hydrocarbons (6) or the Methanol to Olefins (MTO) process (7). Here we consider Fischer-Tropsch to Olefins (FTO) as a direct route, without intermediate steps, to transform syngas into light olefins.

For several decades research groups have attempted to develop iron-based catalysts to direct product selectivity of the FT synthesis towards light olefins $(8,9)$. Compared to other FT catalysts such as cobalt, iron disfavors competing formation of methane, and furthermore catalyzes the water-gas shift (WGS) reaction, enabling the use of a CO-rich syngas feed without an $\mathrm{H}_{2} / \mathrm{CO}$ ratio adjustment. Mainly unsupported (sometimes referred to as bulk) iron oxide catalysts have been investigated (9-12), and in some cases exhibited high selectivities towards lower olefins (up to $70 \mathrm{wt} \%$ ) when the iron was modified by the addition of promoters (9). Despite of these promising results however the bulk iron catalysts are mechanically unstable when the reaction is performed at high temperature, which is necessary to steer product selectivity to lighter hydrocarbons. Under these conditions the undesirable Boudouard reaction, $2 \mathrm{CO}(\mathrm{g}) \rightarrow \mathrm{C}(\mathrm{s})+\mathrm{CO}_{2}(\mathrm{~g})$ (13), leads to the deposition of carbon, which can block the active sites and induce fragmentation of the particles in bulk iron catalysts (14). The poor mechanical stability of the bulk iron oxide catalysts may lead to pressure drop increase in fixed bed operation caused by the plugging of the catalyst bed or to fouling of separation equipment in a fluidized bed process. 
Supported iron catalysts display enhanced dispersion of the active phase and may withstand the mechanical degradation that threatens bulk iron catalysts. Research on supported iron catalysts (15-21) has met with limited success, however. Barrault et al. (15) found that iron dispersed on high surface area alumina displayed much lower activity than that dispersed on low surface area alumina. This finding points to a key aspect of supported iron catalysts, that is their cumbersome activation. If highly dispersed iron oxide interacts strongly with a high surface area oxidic support, the conversion of iron oxide into the active phase (iron carbide) is impeded (14). Next to alumina $(15,16)$, zeolites (18), aluminophosphate molecular sieves (19) and carbonaceous materials $(20,21)$ have been explored as catalyst supports for iron-based FTO catalysts. Table S1 summarizes the most relevant results reported in literature regarding the development of supported iron catalysts for the selective production of lower olefins using carbon or alumina as a support. Iron supported on activated carbon (AC) displayed a high catalytic activity but also either low selectivity to light olefins (20) or a high deactivation rate (21). After many years of research it has been regularly observed that supported iron catalysts which are the most active are the least selective (15).

To overcome the low activity and the mechanical stability problems, we explored the use of support materials weakly interactive toward iron. As a working hypothesis we posited that these inert supports would impart mechanical stability to the iron nanoparticles without inhibiting their activation. In particular, nanostructured carbon materials $(22)$ such as carbon nanofibers (CNF) $(23,24)$ or nanotubes (CNT) (25) boast high specific surface area, chemical inertness and good mechanical strength.

In addition to carbon nanofibers we explored $\beta$-silicon carbide and $\alpha$-alumina as supports. For comparison, we also examined three bulk iron catalysts (one unpromoted and two promoted) and iron supported on conventional high surface area $\mathrm{SiO}_{2}$ and $\gamma-\mathrm{Al}_{2} \mathrm{O}_{3}$. The supported $\mathrm{Fe}$ catalysts were prepared using ammonium iron citrate as precursor with a nominal iron loading of $10 \mathrm{wt} \%$, whereas the bulk catalysts had an iron content higher than $30 \mathrm{wt} \%$ (Table S2). The ammonium iron citrate used in the 
preparation of the supported samples contained low amounts of sulphur and sodium and efficiently introduced these promoters in the catalysts (Table S3).
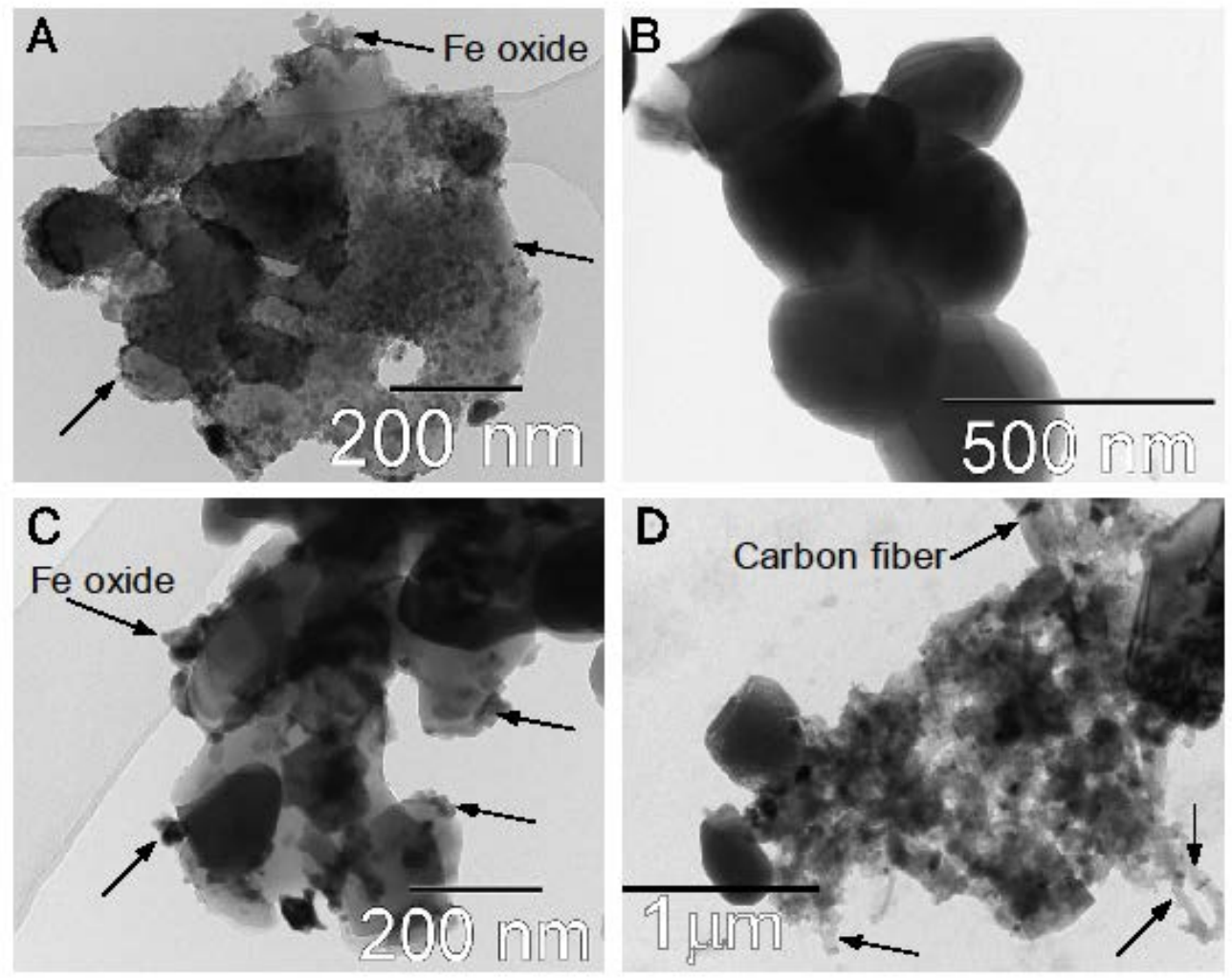

Figure 1. TEM images of fresh and spent Fe catalysts. The images from the fresh $\mathrm{Fe} / \alpha-\mathrm{Al}_{2} \mathrm{O}_{3}$ catalysts (A) show a homogeneous distribution of iron oxide nanoparticles on the support, whereas the bulk Fe-Ti-Zn-K catalyst (B) is mainly composed of aggregates of iron oxide crystals. In images of the spent catalysts after $64 \mathrm{~h}$ of reaction at $340^{\circ} \mathrm{C}, 20$ bar and a $\mathrm{H}_{2} / \mathrm{CO}$ ratio of 1 , the $\mathrm{Fe} / \alpha-\mathrm{Al}_{2} \mathrm{O}_{3}(\mathbf{C})$ showed sintering of $\mathrm{Fe}$ particles after reaction; the bulk spent catalyst (D) fragmented and manifested carbon fiber growth (indicated by arrows).

The use of ammonium iron citrate as the metal precursor provides a homogeneous distribution of the iron nanoparticles on the support, in contrast to extensive clustering that is observed when using iron nitrate (26). Fe nanoparticle aggregation could lead to low catalytic activity and high methane selectivity 
as observed when using bulk iron catalysts. Transmission electron microscopy (TEM) was used to determine the size of the iron oxide particles and their distribution on the support.

Figure $1 \mathrm{~A}$ shows a representative TEM micrograph of the calcined $\mathrm{Fe} / \alpha-\mathrm{Al}_{2} \mathrm{O}_{3}$, which exhibited a homogeneous distribution of iron oxide particles. The $\mathrm{Fe}_{2} \mathrm{O}_{3}$ particle size distribution (Fig. S2) was $14 \pm 5$ $\mathrm{nm}$ on this support, and $5 \pm 1 \mathrm{~nm}$ on CNF. The bulk promoted catalyst (Fe-Ti-Zn-K) consisted of large $\mathrm{Fe}_{2} \mathrm{O}_{3}$ particles (Average size: $400 \mathrm{~nm}$ ), which formed aggregates resembling grape bunches (Fig.1B).

The volume averaged $\mathrm{Fe}_{2} \mathrm{O}_{3}$ crystallite size of the Fe catalyst precursors was calculated with the Scherrer equation using the parameters obtained by X-ray diffraction (XRD) analysis (Fig. S3 and Table $\mathrm{S} 2) . \mathrm{Fe} / \mathrm{SiO}_{2}, \mathrm{Fe} / \gamma-\mathrm{Al}_{2} \mathrm{O}_{3}$ and $\mathrm{Fe} / \beta-\mathrm{SiC}$ did not show the characteristic diffraction lines from iron oxide, indicating that the $\mathrm{Fe}_{2} \mathrm{O}_{3}$ was amorphous or that the crystallites were smaller than $4 \mathrm{~nm}$ (Fig. S3).

The fresh catalysts were also analyzed by Mössbauer spectroscopy to determine the composition of the iron phase (Tables S4 and S5). Iron was present in the form of hematite $\left(\alpha-\mathrm{Fe}_{2} \mathrm{O}_{3}\right)$ in all samples. A superparamagnetic (SPM) iron oxide phase $\left(\alpha-\mathrm{Fe}_{2} \mathrm{O}_{3} \mathrm{SPM}\right)$ was measured in $\mathrm{Fe}_{2} \mathrm{O}_{3}$ particles smaller than $13.5 \mathrm{~nm}$ (supporting text accompanying Table S4). Iron was highly dispersed on CNF, $\gamma-\mathrm{Al}_{2} \mathrm{O}_{3}$ and $\mathrm{SiO}_{2}$, as evidenced by the presence of SPM nanoparticles exclusively. The iron oxide particles on $\alpha-$ $\mathrm{Al}_{2} \mathrm{O}_{3}$ and $\beta$-SiC had a broader size distribution, whereas the bulk Fe-Ti-Zn-K catalyst was primarily composed of large $\mathrm{Fe}_{2} \mathrm{O}_{3}$ particles.

The supported and bulk Fe catalysts were tested in the Fischer-Tropsch reaction at 1 bar and $350^{\circ} \mathrm{C}$ at low $\mathrm{CO}$ conversion $(0.5$ to $1 \%)$ to restrict secondary hydrogenation of olefins (Fig. S4 and Table 1). Catalytic activity is expressed as iron time yield (FTY), i.e. the number of CO moles converted to hydrocarbons per gram of iron per second. A high initial activity was observed for $\mathrm{Fe} / \beta-\mathrm{SiC}$ and $\mathrm{Fe} / \mathrm{CNF}$. The activity of the Fe/CNF decreased continuously during the $15 \mathrm{~h}$ of reaction; the activity of the $\mathrm{Fe} / \beta$ $\mathrm{SiC}$ catalyst increased during the first 5 hours of reaction, then decreased slowly afterwards (Fig. S4A). The Fe/ $\alpha-\mathrm{Al}_{2} \mathrm{O}_{3}$ exhibited a lower catalytic activity than $\mathrm{Fe} / \mathrm{CNF}$ and $\mathrm{Fe} / \beta-\mathrm{SiC}$; however, it showed remarkable stability, as the activity remained constant over 15 hours. $\mathrm{Fe} / \gamma-\mathrm{Al}_{2} \mathrm{O}_{3}$ and $\mathrm{Fe} / \mathrm{SiO}{ }_{2}$ displayed a 
low catalytic activity, comparable to the bulk Fe catalysts (Fig. S4B). The Fe-Cu-K-SiO ${ }_{2}$ catalysts showed an initial activity approximately 4 times higher than the Fe-Ti-Zn-K catalyst. Nevertheless, the iron time yield decreased rapidly to achieve comparable values after $15 \mathrm{~h}$ of reaction.

One of the most important requirements for an FTO catalyst is to obtain the maximum production of the lower olefins fraction while limiting methane selectivity to the lowest level possible. Fe/CNF and $\mathrm{Fe} / \alpha-\mathrm{Al}_{2} \mathrm{O}_{3}$, exhibited high selectivity towards lower olefins $(\sim 60 \% \mathrm{C})$ while directing comparatively little carbon to methane $(<25 \% \mathrm{C}$ ) (Table 1$)$. Fe/ $\beta-\mathrm{SiC}$ and $\mathrm{Fe} / \mathrm{SiO}_{2}$ also showed high selectivity to $\mathrm{C}_{2}$ through $\mathrm{C}_{4}$ olefins but the $\mathrm{CH}_{4}$ product fraction was higher than $30 \% \mathrm{C} . \mathrm{Fe} / \gamma-\mathrm{Al}_{2} \mathrm{O}_{3}$ and the bulk catalysts displayed a high selectivity to methane $(>40 \% \mathrm{C})$ which is not desired for their application in the FTO process.

Additional tests were carried out at 20 bar, $340^{\circ} \mathrm{C}$ and an $\mathrm{H}_{2} / \mathrm{CO}$ ratio of 1 to observe the performance of supported and bulk Fe catalysts under industrially relevant conditions (Fig. 2). In view of the promising results obtained at 1 bar, we prepared and tested additional $\alpha-\mathrm{Al}_{2} \mathrm{O}_{3}$ supported catalysts with different iron loadings ( 6 and $25 \mathrm{wt} \% \mathrm{Fe}$ ) to study the effect of iron content on catalytic performance. Most of the catalysts showed an initial increase in activity, except for the unpromoted bulk Fe (Fig. 2B) which exhibited a decrease in activity during the first $10 \mathrm{~h}$ of reaction before reaching stability. After an initial activation period, $\mathrm{Fe} / \beta-\mathrm{SiC}, \mathrm{Fe} / \mathrm{CNF}, 25 \mathrm{wt} \% \mathrm{Fe} / \alpha-\mathrm{Al}_{2} \mathrm{O}_{3}$ and $\mathrm{Fe} / \gamma-\mathrm{Al}_{2} \mathrm{O}_{3}$ showed a stable catalytic activity for $60 \mathrm{~h}$. A slight decrease in activity during reaction was observed for the $6 \mathrm{wt} \%$ and $12 \mathrm{wt} \% \mathrm{Fe} / \alpha-\mathrm{Al}_{2} \mathrm{O}_{3}$ catalysts mainly due to a continuous drop in $\mathrm{CH}_{4}$ production (Fig. 2C). The stability maintained during 60 hours fully complies with the requirements for the application of these catalysts in fluidized bed reactors. In view of their favorable heat transfer characteristics, it is expected that these reactors will be preferred in industrial application of the exothermic FTO process. 

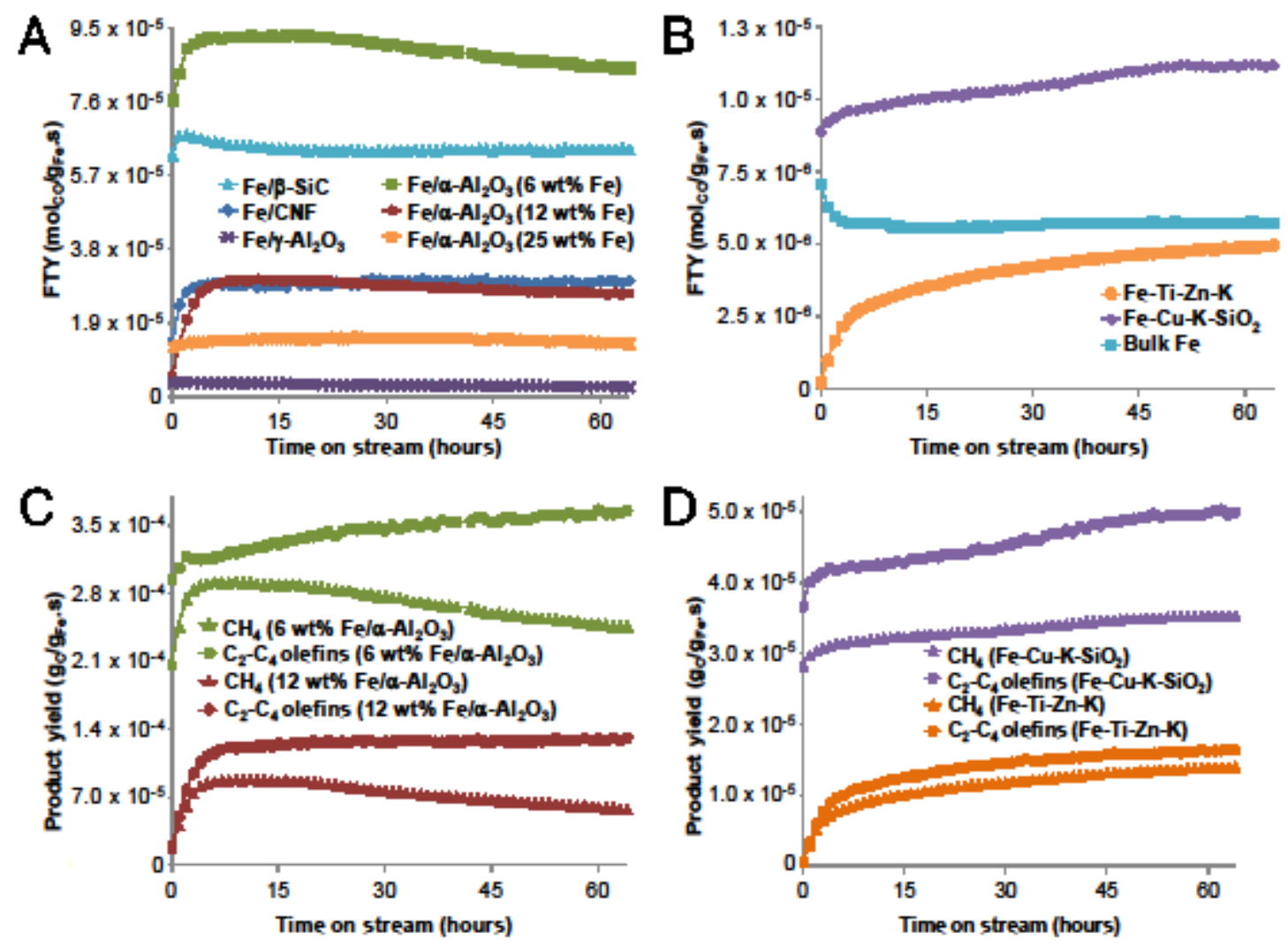

Figure 2. Catalytic performance of iron catalysts for the Fischer-Tropsch to Olefins process at 20 bar.

Catalytic tests were carried out at $\mathrm{T}=340^{\circ} \mathrm{C}, \mathrm{P}=20 \mathrm{bar}, \mathrm{H}_{2} / \mathrm{CO}$ ratio of 1 . Iron time yield is plotted above as a function of time for (A) Fe supported catalysts and (B) bulk Fe catalysts. Methane and lower olefins yields are plotted below as a function of time for (C) Fe supported catalysts and (D) bulk Fe catalysts. The product yields were obtained at CO conversion levels between 70 and $80 \%$.

Table 2 summarizes the activities and product selectivities measured after $64 \mathrm{~h}$ of reaction at 20 bar. The $\mathrm{CO}_{2}$ selectivity for all the samples was approximately $40 \%$ on the basis of $\mathrm{CO}$ converted except for $\mathrm{Fe} / \gamma-\mathrm{Al}_{2} \mathrm{O}_{3}$ (Table S6). Under the selected reaction conditions, most of the catalysts had comparable $\mathrm{CO}$ conversion levels ( 77 to $81 \%$, Table $\mathrm{S} 6$ ). However, the $\mathrm{Fe} / \gamma-\mathrm{Al}_{2} \mathrm{O}_{3}$ catalyst only achieved a $\mathrm{CO}$ conversion of $10 \%$. The promoted catalysts prepared using supports with low interaction with iron showed high catalytic activities combined with high selectivities to the desired products. Fe/CNF and 25 wt $\% \mathrm{Fe} / \alpha-\mathrm{Al}_{2} \mathrm{O}_{3}$ exhibited high selectivities towards $\mathrm{C}_{2}$ through $\mathrm{C}_{4}$ olefins ( $>50 \% \mathrm{C}$ ) while yielding a 
methane product fraction lower than $15 \% \mathrm{C}$. The $\mathrm{Fe}-\mathrm{Cu}-\mathrm{K}-\mathrm{SiO}_{2}$ catalyst showed a catalytic activity comparable to the $25 \mathrm{wt} \% \mathrm{Fe} / \alpha-\mathrm{Al}_{2} \mathrm{O}_{3}$; however, only moderate selectivities towards lower olefins were obtained.

The Anderson-Schulz-Flory model (Equation S2) that is used to predict the product distribution indicates that the maximum selectivity achievable for the $\mathrm{C}_{2}-\mathrm{C}_{4}$ fraction, including olefins and paraffins, is approximately $50 \mathrm{wt} \%$, at a chain growth probability $(\alpha)$ between 0.4 to 0.5 , as shown in Figure S5. This model predicts that methane selectivity is about $30 \mathrm{wt} \%$ when this maximum $\mathrm{C}_{2}-\mathrm{C}_{4}$ selectivity is reached.

Anderson-Schulz-Flory (ASF) plots (Figures 3 and S6) demonstrate that the catalysts prepared using inert supports provide us with $\alpha$-values of $\sim 0.4$ close to the optimal value for maximum lower olefins production. Moreover, the plots in Fig. 3 revealed lower methane selectivities compared with the values predicted from the ASF model. This can be rationalized from the simplified 'surface carbide' or 'alkyl' mechanism (Fig. S1) which is widely accepted for the Fischer-Tropsch synthesis (13). In this model, following $\mathrm{CO}$ dissociation and carbon hydrogenation, $\mathrm{CH}_{3}$ group adsorbed on the catalyst surface is proposed to act as chain initiator. The carbon chain grows by the addition of methylene monomer units $\left(\mathrm{CH}_{2}\right)$ to the adsorbed alkyl species. The chain growth is terminated by $\beta$-hydride abstraction to form $\alpha$-olefins or by hydrogenation to produce paraffins. Negative deviations from the ASF prediction for methane selectivity can be expected when using iron catalysts modified with promoters which limit the hydrogenation reactions (8) thus favoring chain growth and the termination step via $\beta$ hydride abstraction that cannot give rise to $\mathrm{CH}_{4}$ production. The suppression of the methanation reaction induced by the promoters was only observed when using CNF or $\alpha-\mathrm{Al}_{2} \mathrm{O}_{3}$ since these 'inert' supports are thought to favor the proximity between iron and promoters $(\mathrm{Na}+\mathrm{S})$ in contrast to reactive supports such as $\gamma-\mathrm{Al}_{2} \mathrm{O}_{3}$ which lead to more methane (Fig. 3). In the case of the bulk catalysts, $\mathrm{CH}_{4}$ selectivities coincided with the values predicted by the ASF model or were slightly above. 


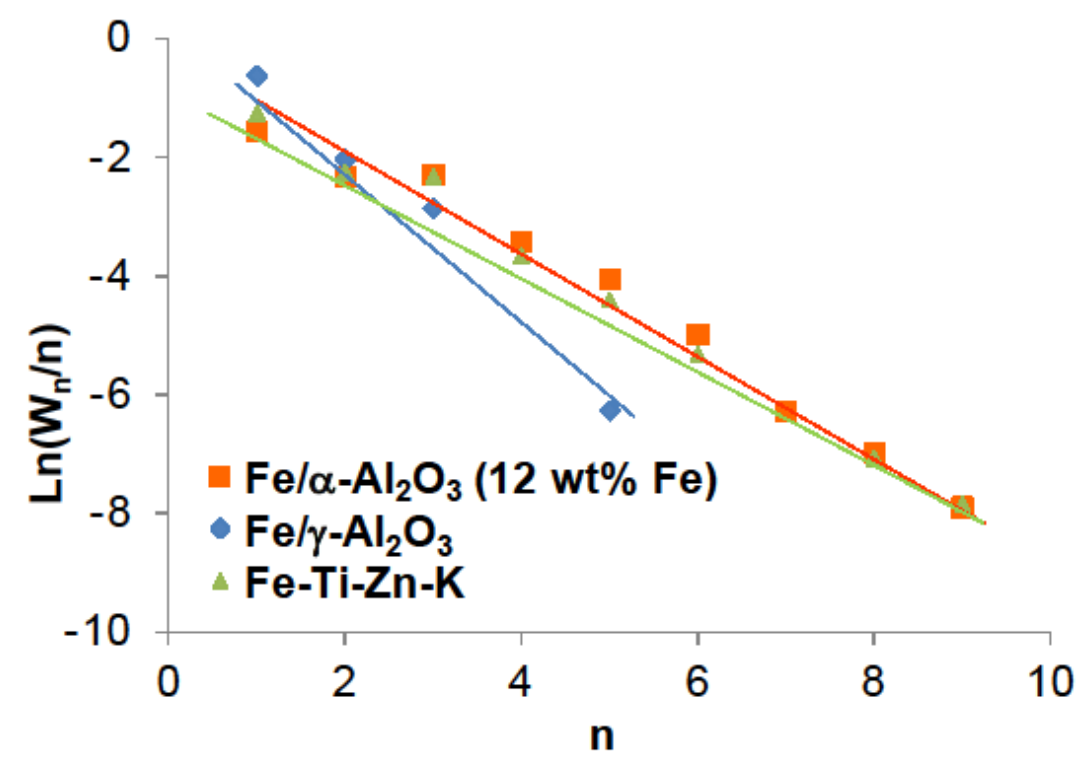

Figure 3. Comparison of ASF plots for supported and bulk catalysts. The ASF plots are based on the product distribution obtained when performing the Fischer-Tropsch reaction at 20 bar, $340^{\circ} \mathrm{C}$ and $\mathrm{H}_{2} / \mathrm{CO}$ ratio of 1 after $64 \mathrm{~h}$ time on stream. Fe/ $\alpha-\mathrm{Al}_{2} \mathrm{O}_{3}$ has an iron loading of $12 \mathrm{wt} \% ; \mathrm{n}$ is the number of carbon atoms in a product and $\mathrm{W}_{\mathrm{n}}$ is the weight fraction of the product with carbon number equal to $\mathrm{n}$.

Mössbauer spectroscopy of the spent catalysts after reaction at 1 bar (Table S5) showed that the nature of the iron phases varied when using different support materials. Although some of the iron carbides may be oxidized after exposure to air, $\mathrm{Fe}_{\mathrm{x}} \mathrm{C}_{\mathrm{y}}$ was detected on the samples with moderate to high catalytic activity. In contrast, the samples with the lowest catalytic activity, $\mathrm{Fe} / \mathrm{SiO}{ }_{2}$ and $\mathrm{Fe} / \gamma-\mathrm{Al}_{2} \mathrm{O}_{3}$, did not contain any carbides. A strong metal-support interaction clearly inhibits the formation of catalytically active iron carbides as observed for conventional high surface area support materials. Please note that in the size range of iron particles dispersed on inert supports $(7-20 \mathrm{~nm})$ particle size effects seem to be minimal.

TEM performed on spent catalysts revealed size increase of the iron nanoparticles in the supported samples. The particle size distributions of the fresh and spent $\mathrm{Fe} / \alpha-\mathrm{Al}_{2} \mathrm{O}_{3}$ and $\mathrm{Fe} / \mathrm{CNF}$ are 
shown in Figure S2. For Fe/CNF, changes in the catalytic activity were only observed during the first 4 hours of reaction, suggesting that the changes in the catalyst structure took place during catalyst activation and initial usage. In the case of $\mathrm{Fe} / \alpha-\mathrm{Al}_{2} \mathrm{O}_{3}$, the average iron nanoparticle size increased from $14 \pm 5 \mathrm{~nm}$ to $17 \pm 5 \mathrm{~nm}$ (Fig. 1C). The promoted bulk iron oxide showed extensive particle fragmentation and carbon filament growth, which brings about the poor mechanical stability of this catalyst (Fig. 1D).

The spent catalysts were characterized with thermogravimetric analysis (TGA) to determine the extent of carbon lay-down. Carbon burn-off experiments were performed for all the samples, except for the Fe/CNF catalyst. Although extensive carbon deposition on the samples after reaction with CO-rich syngas and high temperatures could be expected, most of the samples exhibited low solid carbon formation. After $64 \mathrm{~h}$ of reaction at $340^{\circ} \mathrm{C}$ and $20 \mathrm{bar}$, the levels of carbon lay-down measured on the spent catalysts were lower than $10 \mathrm{wt} \%$. In contrast, $\mathrm{Fe} / \alpha-\mathrm{Al}_{2} \mathrm{O}_{3}(25 \mathrm{wt} \% \mathrm{Fe})$ and $\mathrm{Fe}-\mathrm{Cu}-\mathrm{K}-\mathrm{SiO}_{2}$ exhibited a higher extent of coke formation ( $23 \mathrm{wt} \%$ and $40 \mathrm{wt} \%$, respectively).

The Fischer-Tropsch to Olefins (FTO) process arises as a strong alternative route for the sustainable production of lower olefins from biomass-derived synthesis gas. The industrial potential of this process is greatly enhanced by the reported development of active, selective and mechanically stable catalysts that consist of promoted iron nanoparticles dispersed on weakly interactive supports. Further suppression of methane production, maximization of the $\mathrm{C}_{2}-\mathrm{C}_{4}$ olefins fraction and reduction of carbon lay-down by addition of promoters and by optimization of physical properties (e.g., Fe particle size, distribution of Fe nanoparticles on the support) will allow us to further understand and develop the performance of these catalysts. 
Table 1. Product selectivity and catalytic activity at 1 bar. Catalytic tests performed at $350^{\circ} \mathrm{C}$ and $\mathrm{H}_{2} / \mathrm{CO}$ ratio of 1 ; results after $15 \mathrm{~h}$ on stream (CO conversion: $0.5-1.0 \%)$. The product mixture that was analyzed consisted of $\mathrm{C}_{1}$ to $\mathrm{C}_{16}$ hydrocarbons. Iron time yield (FTY): moles of $\mathrm{CO}$ converted to hydrocarbons per mol of Fe per second. $\% \mathrm{C}$ is defined as carbon atoms in a product with respect to the total number of $\mathrm{C}$ atoms in the hydrocarbon mixture. $\mathrm{CO}_{2}$ was not measured.

\begin{tabular}{lccccc}
\hline \multirow{2}{*}{ Sample } & $\mathrm{FTY}$ & \multicolumn{4}{c}{ Selectivity $(\% \mathrm{C})$} \\
\cline { 3 - 6 } & $\left(10^{-6} \mathrm{~mol}_{\mathrm{CO}} / \mathrm{g}_{\mathrm{Fe}} . \mathrm{s}\right)$ & $\mathrm{CH}_{4}$ & $\mathrm{C}_{2}-\mathrm{C}_{4}$ olefins & $\mathrm{C}_{2}-\mathrm{C}_{4}$ paraffins & $\mathrm{C}_{5+}$ \\
\hline $\mathrm{Fe} / \mathrm{CNF}$ & 1.41 & 23 & 61 & 4 & 12 \\
$\mathrm{Fe} / \alpha-\mathrm{Al}_{2} \mathrm{O}_{3}(12 \mathrm{wt} \% \mathrm{Fe})$ & 0.65 & 22 & 61 & 4 & 13 \\
$\mathrm{Fe} / \beta-\mathrm{SiC}$ & 6.52 & 31 & 58 & 4 & 7 \\
$\mathrm{Fe} / \mathrm{SiO}_{2}$ & 0.14 & 38 & 56 & 5 & 1 \\
$\mathrm{Fe} / \gamma-\mathrm{Al}_{2} \mathrm{O}_{3}$ & 0.07 & 54 & 44 & 2 & 0 \\
$\mathrm{Fe}-\mathrm{Ti}-\mathrm{Zn}-\mathrm{K}$ & 0.13 & 83 & 16 & 1 & 0 \\
$\mathrm{Fe}-\mathrm{Cu}-\mathrm{K}-\mathrm{SiO}_{2}$ & 0.20 & 43 & 46 & 2 & 9 \\
$\mathrm{Bulk} \mathrm{Fe}$ & 0.08 & 76 & 21 & 2 & 1 \\
\hline
\end{tabular}


Table 2. Catalytic performance at 20 bar. Catalytic tests performed at $340^{\circ} \mathrm{C}$ and $\mathrm{H}_{2} / \mathrm{CO}$ ratio of 1 ; results after $64 \mathrm{~h}$ on stream. The product mixture that was analyzed consisted of $C_{1}$ to $C_{10}$ hydrocarbons. FTY and selectivity defined as in Table 1 . The selectivities were calculated on hydrocarbons produced*.

\begin{tabular}{lcccccc}
\hline & & \multicolumn{5}{c}{ Selectivity $(\% \mathrm{C})$} \\
\cline { 3 - 7 } \multicolumn{1}{c}{ Sample } & $\begin{array}{c}\mathrm{FTY} \\
\left.\mathrm{mol}_{\mathrm{CO}} / \mathrm{g}_{\mathrm{Fe}} \cdot \mathrm{s}\right)\end{array}$ & $\mathrm{CH}_{4}$ & $\begin{array}{c}\mathrm{C}_{2}-\mathrm{C}_{4} \\
\text { olefins }\end{array}$ & $\begin{array}{c}\mathrm{C}_{2}-\mathrm{C}_{4} \\
\text { paraffins }\end{array}$ & $\mathrm{C}_{5+}$ & Oxygenates \\
\hline $\mathrm{Fe} / \mathrm{CNF}$ & 2.98 & 13 & 52 & 12 & 18 & 5 \\
$\mathrm{Fe} / \alpha-\mathrm{Al}_{2} \mathrm{O}_{3}(6 \mathrm{wt} \% \mathrm{Fe})$ & 8.48 & 24 & 35 & 21 & 10 & 10 \\
$\mathrm{Fe} / \alpha-\mathrm{Al}_{2} \mathrm{O}_{3}(12 \mathrm{wt} \% \mathrm{Fe})$ & 2.66 & 17 & 39 & 19 & 14 & 11 \\
$\mathrm{Fe} / \alpha-\mathrm{Al}_{2} \mathrm{O}_{3}(25 \mathrm{wt} \% \mathrm{Fe})$ & 1.35 & 11 & 53 & 6 & 21 & 9 \\
$\mathrm{Fe} / \beta-\mathrm{SiC}$ & 6.38 & 35 & 19 & 39 & 4 & 3 \\
$\mathrm{Fe} / \gamma-\mathrm{Al}_{2} \mathrm{O}_{3}$ & 0.25 & 49 & 33 & 11 & 1 & 6 \\
$\mathrm{Fe}-\mathrm{Ti}-\mathrm{Zn}-\mathrm{K}$ & 0.49 & 24 & 28 & 29 & 10 & 9 \\
$\mathrm{Fe}-\mathrm{Cu}-\mathrm{K}-\mathrm{SiO}_{2}$ & 1.12 & 26 & 36 & 12 & 18 & 8 \\
$\mathrm{Bulk} \mathrm{Fe}$ & 0.57 & 30 & 32 & 18 & 14 & 6 \\
\hline
\end{tabular}

* $\mathrm{CO}$ conversions and $\mathrm{CO}_{2}$ selectivities are reported in Table $\mathrm{S} 6$ 


\section{References and notes}

1. A. Corma, F. V. Melo, L. Sauvanaud, F. Ortega, Light cracked naphtha processing: controlling chemistry for maximum propylene production. Catal. Today 107-108, 699-706 (2005).

2. R. Diercks et al., Raw material changes in the chemical industry. Chem. Eng. Technol. 31, 631-637 (2008).

3. S. Wang, Z. H. Zhu, Catalytic conversion of alkanes to olefins by carbon dioxide dehydrogenation-A review. Energ. Fuel. 18, 1126-1139 (2004).

4. E. L. Kunkes et al., Catalytic conversion of biomass to monofunctional hydrocarbons and targeted liquid-fuel classes. Science 322, 417-421 (2008).

5. T. P. Vispute, H. Zhang, A. Sanna, R. Xiao, G. W. Huber, Renewable chemical commodity feedstocks from integrated catalytic processing of pyrolisis oils. Science 330, 1222-1227 (2010).

6. X. Dupain, R. A. Krul, C. J. Schaverien, M. Makkee, J. A. Moulijn, Production of clean transportation fuels and lower olefins from Fischer-Tropsch Synthesis waxes under fluid catalytic cracking conditions. The potential of highly paraffinic feedstocks for FCC. Appl. Catal. B 63, 277-295 (2006).

7. G. A. Olah, Beyond oil and gas: the methanol economy. Angew. Chem. Int. Ed. 44, 2636-2639 (2005).

8. C. Wang, L. Xu, Q. Wang, Review of directly producing light olefins via CO hydrogenation. J. Nat. Gas Chem. 12, 10-16 (2003).

9. B. Büssemeier, C. D. Frohning, G. Horn, W. Kluy, US Patent 4564642 (1986).

10. B. H. Davis, Fischer-Tropsch synthesis: relationship between iron catalyst composition and process variables. Catal. Today 84, 83-98 (2003).

11. S. Soled, E. Iglesia, Activity and selectivity control in iron catalyzed Fischer-Tropsch synthesis. Catal. Lett. 7, 271-280 (1990). 
12. Y. Jin, A. K. Datye, Phase transformations in iron Fischer-Tropsch catalysts during temperature-programmed reduction. J. Catal. 196, 8-17 (2000).

13. A. P. Steynberg, M. E. Dry, Eds., Fischer-Tropsch Technology (Series: Studies in surface science and catalysis No. 152) (Elsevier, Amsterdam, 2004).

14. M. D. Shroff et al., Activation of precipitated iron Fischer-Tropsch synthesis catalysts. J. Catal. 156, 185-207 (1995).

15. J. Barrault, C. Forquy, J. C. Menezo, R. Maurel, Selective hydrogenation of CO to light olefins with aluminasupported iron catalysts. React. Kinet. Catal. Lett. 15, 153-158 (1980).

16. B. G. Baker, N. J. Clark, H. MacArthur, E. Summerville, US Patent 4610975 (1986).

17. D. B. Bukur et al., Binder/support effects on the activity and selectivity of iron catalysts in the Fischer-Tropsch synthesis. Ind. Eng. Chem. Res. 29, 1588-1599 (1990).

18. L. Xu, Q. Wang, Y. Xu, J. Huang, Promotion effect of $\mathrm{K}_{2} \mathrm{O}$ and $\mathrm{MnO}$ additives on the selective production of light alkenes via syngas over Fe/silicalite-2 catalysts. Catal. Lett. 31, 253-266 (1995).

19. M. L. Cubeiro et al., Use of aluminophosphate molecular sieves in CO hydrogenation. Appl. Catal. A 167, 183193 (1998).

20. V. K. Jones, L. R. Neubauer, C. H. Bartholomew, Effects of crystallite size and support on the CO hydrogenation activity/selectivity properties of Fe/Carbon. J. Phys. Chem. 90, 4832-4839 (1986).

21. A. P. B. Sommen, F. Stoop, K. van der Wiele, Synthesis gas conversion on carbon supported iron catalysts and the nature of deactivation. Appl. Catal. 14, 277-288 (1985).

22. K. P. de Jong, Support materials and characterization for nanostructured catalysts. Oil Gas Sci. Technol. 61, 527534 (2006). 
23. K. P. de Jong, J. W. Geus, Carbon nanofibers: catalytic synthesis and applications. Catal. Rev. Sci. Eng. 42, 481$510(2000)$.

24. E. van Steen, F. F. Prinsloo, Comparison of preparation methods for carbon nanotubes supported iron FischerTropsch catalysts. Catal. Today 71, 327-334 (2002).

25. W. Chen, Z. Fan, X. Pan, X. Bao, Effect of confinement in carbon nanotubes on the activity of Fischer-Tropsch iron catalyst. J. Am. Chem. Soc. 130, $9414-9419$ (2008).

26. A. J. van Dillen, Terörde, Robert J. A. M., D. J. Lensveld, J. W. Geus, K. P. de Jong, Synthesis of supported catalysts by impregnation and drying using aqueous chelated metal complexes. J. Catal. 216, 257-264 (2003).

27. G. L. Bezemer et al., Cobalt particle size effects in the Fischer-Tropsch reaction studied with carbon nanofiber supported catalysts. J. Am. Chem. Soc. 128, 3956-3964 (2006).

28. B. G. Baker, N. J. Clark, H. Macarthur, E. Summerville, WO8400702 (1984).

29. J. M. Martín-Martínez, M. A. Vannice, Carbon-supported iron catalysts: Influence of support porosity and preparation techniques on crystallite size and catalytic behavior. Ind. Eng. Chem. Res. 30, 2275 (1991).

30. R. M. Malek Abbaslou, A. Tavasoli, A. K. Dalai, Effect of pre-treatment on physico-chemical properties and stability of carbon nanotubes supported iron Fischer-Tropsch catalysts. Appl. Catal. A 355, 33-41 (2009).

31. J. Venter, M. Kaminsky, G. L. Geoffroy, M. A. Vannice, Carbon-supported Fe-Mn and K-Fe-Mn clusters for the synthesis of $\mathrm{C}_{2}-\mathrm{C}_{4}$ olefins from $\mathrm{CO}$ and $\mathrm{H}_{2}$. II. Activity and selectivity manteinance and regenerability. J. Catal.

105, 155-162 (1987).

32. M. C. Bahome et al., Fe-Ru small particle bimetallic catalysts supported on carbon nanotubes for use in FischerTropsch synthesis. Appl. Catal. A 328, 243-251 (2007). 
33. H. Xiong, M. Moyo, M. A. M. Motchelaho, L. L. Jewell, N. J. Coville, Fischer-Tropsch synthesis over model iron catalysts supported on carbon spheres: The effect of iron precursor, support treatment, catalyst preparation method and promoters. Appl. Catal. A 388, 168-178 (2010).

34. T. Liu, L. Guo, Y. Tao, Y. B. Wang, W. D. Wang, Synthesis and interfacial structure of nanoparticles $\mathrm{g}^{-\mathrm{Fe}_{2}} \mathrm{O}_{3}$ coated with surfactant DBS and CTAB. Nanostruct. Mater. 11, 487-492 (1999).

35. D. B. Bukur, M. Koranne, X. Lang, Rao, K. R. P. M., G. P. Huffman, Pretreatment effect studies with a precipitated iron Fischer-Tropsch catalyst. Appl. Catal. A 126, 85-113 (1995).

36. Materials and methods are available as supporting material on Science Online.

Acknowledgments: The authors thank the ACTS-ASPECT (NWO) program for funding this project. We thank M. Van de Vijver for the catalytic tests at 20 bar performed at DOW Benelux, Prof. Dr. Ir. E. J. M. Hensen (Technical University of Eindhoven) for his contribution in the discussion of the Mössbauer Spectroscopy results, and C. van der Spek (Utrecht University) for the TEM images. KPdJ acknowledges support from NWO-TOP and NRSCC. ACTS-ASPECT (NWO) has filed a patent application based on the work reported here.

\section{Supporting Online Material}

www.sciencemag.org

Materials and Methods

Tables S1 to S6

Equations S1 and S2

Figs. S1 to S6

References (28-35) 